\title{
Desfazendo o "Mau-olhado": Magia, Saúde e Desenvolvimento no Ofício das Benzedeiras
}

\author{
Raquel Cornélio Marin \\ Fabio Scorsolini-Comin \\ Universidade Federal do Triângulo Mineiro, MG, Brasil. $\quad$ Universidade Federal do Triângulo Mineiro, MG, Brasil.
}

\begin{abstract}
Resumo: $\mathrm{O}$ objetivo deste estudo é compreender as experiências (pessoais, religiosas, sociais e culturais) e as transformações desenvolvimentais das benzedeiras ao longo de suas trajetórias de vida, bem como sua relação com a promoção da saúde em suas comunidades. Foram entrevistadas 10 benzedeiras residentes em cidades do interior dos estados de São Paulo e Minas Gerais, com média de 62,5 anos de idade e de 26,2 anos de ofício. O referencial teórico empregado foi o da Rede de Significações, associado às contribuições etnopsicológicas. A maioria relatou a transmissão do ofício a partir de um familiar, destacando a prática da benzeção como algo que pode ser ensinado, aprendido e transmitido por meio da tradição oral. Mesmo assim, o ofício também é compreendido como um dom inato que atravessa o desenvolvimento, o que requer dedicação, paciência e abnegação. A dificuldade de transmitir o ofício aos mais jovens pode estar relacionada a uma maior urbanização, ao maior acesso a equipamentos formais de saúde, bem como revela a submissão da benzeção a uma lógica biomédica, dentro de um sistema de saúde que, por vezes, negligencia os sistemas populares de cuidado.
\end{abstract}

Palavras-chave: Práticas Religiosas; Rituais de Cura; Religião e Saúde Mental; Psicologia do Desenvolvimento.

\section{Undoing the "Evil eye": Magic, Health and Development in the Craft of Folk Healers}

\begin{abstract}
The objective of this study is to understand the experiences (personal, religious, social and cultural) and the developmental transformations of the folk healers throughout their life trajectories, as well as their relation with the promotion of health in their communities. Ten folk healers were interviewed in cities in the interior of the states of São Paulo and Minas Gerais, with a mean age of 62.5 years and a mean of 26.2 years in office. The theoretical reference used was that of the Network of Meanings, associated to ethnopsychological contributions. Most reported transmission of the craft from a family member, highlighting the practice of folk healing as something that can be taught, learned and transmitted through oral tradition. Still, the craft is understood as a gift that runs through the development, which requires dedication, patience and self-denial. The difficulty of transmitting the job to the younger ones may be related to greater urbanization, greater access to formal health equipment, as well as revealing the submission of the blessing to a biomedical logic, within a health system that sometimes neglects popular systems of care.
\end{abstract}

Keywords: Religious Practices; Healing Rituals; Religion and Mental Health; Developmental Psychology. 


\title{
Deshaciendo el "Mal de ojo": la Magia, la Salud y el Desarrollo en el Oficio de las Curanderas
}

\begin{abstract}
Resumen: El objetivo del artículo es comprender las experiencias (personales, religiosas, sociales y culturales) y las transformaciones de desarrollo de las curanderas en el transcurso de sus trayectorias de vida, así como su relación con la promoción de la salud en sus comunidades. Se entrevistó a 10 curanderas, con una media de 62,5 años de edad y 26,2 años en el oficio, residentes en ciudades del interior de los Estados de São Paulo y Minas Gerais. El marco teórico utilizado fue la Red de Significados, asociado con contribuciones etnopsicológicas. La mayoría informó la transmisión del oficio de un miembro de la familia, destacando la práctica de curandería como algo que se puede enseñar, aprender y transmitir a través de la tradición oral. Aun así, el oficio se entiende como un regalo que atraviesa el desarrollo, que requiere dedicación, paciencia y abnegación. La dificultad de la transmisión del oficio a la gente más joven puede estar relacionada con el aumento de la urbanización, un mayor acceso a los servicios de salud formales, así como revelar la sumisión a una lógica biomédica dentro de un sistema de salud que a veces deja de lado los sistemas populares del cuidado.
\end{abstract}

Palabras clave: Prácticas Religiosas; Rituales de Curación; Religión y Salud Mental; Psicología del Desarollo.

A ciência psicológica vem conferindo cada vez mais destaque aos estudos que consideram a espiritualidade como importante elemento de saúde e bem-estar. Ganham relevância, nesse contexto, as investigações que buscam retratar de que modo tais aspectos circunscrevem o desenvolvimento humano a partir, por exemplo, de experiências relacionadas à mediunidade e às práticas de benzeção e magia (Scorsolini-Comin, 2015; Winkelman, 2002). No presente estudo, o foco recai sobre as benzedeiras, importantes figuras que compõem o cenário da cultura popular brasileira (Borges, 2008; Borges, Shimizu, \& Pinho, 2009; Lins, 2013; Moura, 2009; Nunes, Magalhães, \& Rocha, 2013). As práticas de benzeção ultrapassam gerações, despertando tanto o interesse por seus aspectos culturais como também por suas manifestações psicofisiológicas (Winkelman, 2002).

A benzeção ou benzimento, como outras práticas religiosas e médicas populares, começou a se desenvolver no Brasil ainda no período colonial, no século XVII. Para Ribeiro (1997, p. 16), os fatores que propiciaram o seu desenvolvimento foram "a precariedade da vida material, marcada pela raridade de médicos, cirurgiões e produtos farmacêuticos, e o sincretismo dos povos, responsável pela formação multifacetada e afeita ao universo da magia". No entanto, não apenas a escassez de recursos médicos tradicionais propiciou a propagação oral de conhecimentos sobre o uso medi- cinal de plantas, raízes, ervas, essências e orações, mas também um universo mítico rico povoado por lendas, crenças e espiritualidade (Campos, 1967; Silva, 2007).

Estudos internacionais revelam que não somente no Brasil essas práticas populares de cura foram as primeiras formas de cuidado e atenção para com os adoentados. Segundo Ryan (1999), os xamãs foram os primeiros psicoterapeutas, médicos, mágicos, artistas performáticos, contadores de histórias e até mesmo os primeiros previsores do tempo da humanidade. Para Laplantine (2010), as práticas médicas e as mágico-religiosas seriam complementares, sendo que a medicina popular associaria os sintomas físicos a uma série de queixas não apenas somáticas, mas também psicológicas, sociais, espirituais e existenciais nem sempre reconhecidas pelo racionalismo social.

A benzeção pode ser caracterizada como uma atividade principalmente terapêutica, a qual se realiza através de uma relação dual entre cliente e benzedor. Nessa relação, a benzedeira exerce um papel de intermediação entre o sagrado e o humano objetivando a cura, e essa terapêutica tem como processo principal o uso de algum tipo de prece (Quintana, 1999). Trata-se de práticas que incidem sobre o corpo físico e espiritual, relacionadas à cura e promoção do bem-estar, administradas por pessoas que possuem conhecimentos formais e informais acerca dessas práticas, muitos 
dos quais transmitidos pela tradição oral (Rubert, 2014; Simões, 2014). Segundo Theotonio (2010), popularmente a prática da reza tem como objetivo curar, aliviar a dor ou a angústia de sentir algo que incomoda.

Os benzedores e benzedeiras são encontrados em grande número em comunidades rurais e na periferia das cidades, e nesse espaço são muito valorizados e respeitados, exercendo papel de conselheiros em questões que vão desde a perda de objetos pessoais, dificuldades do matrimônio, dificuldades financeiras e, claro, problemas de saúde e espirituais. O curandeiro, raizeiro ou benzedeiro era visto como alguém possuidor de um conhecimento capaz de restaurar o equilíbrio, restituir a saúde, assim como também desencadear malefícios, em um equivalente ao ofício do feiticeiro ou do xamã em comunidades consideradas primitivas (Lévi-Strauss, 1975). Desde então, uma imagem negativa é muitas vezes vinculada às benzedeiras, como se quem pudesse ajudar tivesse também o poder de destruir se assim quisesse.

Antigamente a prática da benzeção era prioritariamente católica, o que restringia o local da prática às Igrejas e santuários, sendo que, mais recentemente, religiões como a umbanda, o candomblé, os pentecostais e o kardecismo começaram a multiplicar as possibilidades de rituais, de significados e de desenvolvimento dessas práticas (Oliveira, 1985). Desse encontro de diferentes religiões surgiu uma pluralidade de práticas sem que se perdesse a tradição do ritual, atualizando processos que atravessam os tempos.

O desenvolvimento de uma benzedeira é um processo que acontece ao longo do tempo, permeado por transformações sociais, psicológicas, emocionais e espirituais, inclusive no que se refere ao reconhecimento público de sua comunidade local. Segundo Oliveira (1985), a imagem que as benzedeiras trazem de si é geralmente de serem pessoas solícitas, dispostas a ajudar o outro e essencialmente boas. São consideradas capazes de intermediar a cura, uma vez que quem cura não é a própria pessoa, mas sim a divindade de quem a benzedeira é instrumento (Silva, 2007). As benzedeiras representam para seus clientes um canal entre o humano e o sagrado, sendo que ignorar suas recomendações equivaleria a ignorar a própria divindade (Medeiros, Nascimento, Diniz, \& Alchieri, 2013).

Embora sejam encontrados estudos que destaquem os aspectos sociais da benzeção, assim como as práticas de saúde e cuidado veiculadas por meio de sua atuação, ainda são encontradas poucas investiga- ções que considerem o desenvolvimento pessoal dessas benzedeiras, objeto de particular interesse da ciência psicológica. As práticas de saúde veiculadas pelas benzedeiras mesclam conhecimentos que remetem ao empírico e ao científico, com grande destaque para a crença no método, no poder do ritual, o que se mistura com processos afetivos desse cuidar (Medeiros et al., 2013). Para Helman (2009), as benzedeiras fazem parte das subculturas de cuidado em saúde, especificamente dentro do setor popular (folk), intermediário entre os sistemas formal e profissional, apresentando entre suas características o envolvimento da família nos processos de diagnóstico e tratamento, maior proximidade afetiva, uso de linguagem acessível e oferta de explicações para o adoecimento que são amplamente compartilhadas por suas comunidades de referência. A partir dos apontamentos de Laplantine (2010), podemos compreender que as benzedeiras, dentro desse sistema popular de cuidado, permitem uma leitura sobre saúde e adoecimento que ultrapassa a causalidade biomédica e isenta de representações, incorporando uma noção de doença como fenômeno social prenhe de significações.

Tais processos afetivos relacionam-se tanto à imagem social construída em torno das benzedeiras quanto de elementos que recobrem seus processos desenvolvimentais, que se mostram de modo muito heterogêneo (Helman, 2009). Investigar os percursos desenvolvimentais de benzedeiras revela-se, portanto, uma forma de conferir visibilidade a elas, bem como discutir de que modo a tradição oral e as práticas de medicina popular contribuem para a transmissão desse ofício e sua presença em determinadas comunidades como sinônimos de promoção de bem-estar e cura, em um sistema popular (folk) de saúde. A partir do exposto, o objetivo deste estudo foi compreender as experiências (pessoais, religiosas, sociais e culturais) e as transformações desenvolvimentais das benzedeiras ao longo de suas trajetórias de vida, bem como sua relação com a promoção da saúde em suas comunidades.

\section{Método}

\section{Tipo de estudo e participantes}

Este estudo descritivo e exploratório, amparado na abordagem qualitativa de pesquisa, de corte transversal, contou com a participação de benzedeiras atuantes, sem restrição de religião professada, sexo, grau 
de instrução, classificação socioeconômica e idade máxima, desde que fossem maiores de idade e aceitassem participar voluntariamente da pesquisa a partir dos termos descritos no Termo de Consentimento Livre e Esclarecido. Participaram do estudo 10 benzedeiras na faixa etária entre 48 e 76 anos $(\mathrm{m}=62,5)$, variando o tempo de experiência e atuação como benzedeira entre seis e 64 anos $(m=26,2)$ em suas comunidades. O estudo foi aprovado pelo Comitê de Ética em Pesquisa da instituição de origem dos autores.

\section{Instrumentos}

Os instrumentos utilizados foram a Técnica da História de Vida e um roteiro de entrevista semiestruturado construído especificamente para esta investigação. A adoção da Técnica da História de Vida visou conhecer os principais eventos de vida das participantes a partir do modo como elas próprias recontam a sua trajetória, com o emprego da pergunta disparadora: "Conte-me, com suas próprias palavras e do modo como preferir, a sua história de vida até o momento". Essa narrativa poderia incluir menções a diferentes etapas do ciclo vital, pessoas consideradas importantes, experiências marcantes, bem como aspectos mais diretamente relacionados aos objetivos do estudo, ou seja, as principais práticas de benzeção e o modo como as mesmas atravessam o percurso de vida das benzedeiras. Tal instrumento mostrou-se adequado na medida em que tais práticas são mantidas, transmitidas, recriadas e baseadas na oralidade (Boyer, 1996). O roteiro de entrevista continha questões acerca do desenvolvimento pessoal da mediunidade, o desenvolvimento das práticas de benzeção, bem como explorou questões como as concepções de saúde e de cura veiculadas pelas participantes.

\section{Procedimento}

\section{Coleta de dados}

As participantes foram recrutadas a partir da rede social dos pesquisadores, por meio de indicações de pessoas da comunidade local e do procedimento "bola de neve", em que os próprios participantes indicavam outros potenciais entrevistados. A coleta foi realizada em duas cidades do interior do estado de São Paulo e uma no estado de Minas Gerais. Após o primeiro contato com as participantes e do convite formal para a pesquisa, foram marcadas as entrevistas, ocorridas na residência das participantes. Pediu-se que elas lessem e assinassem o Termo de Consentimento Livre e Esclarecido e que esclarecessem qualquer dúvida que as acometessem a respeito da pesquisa. Depois, dava-se início à entrevista, começando pela Técnica da História de Vida, seguida pelo roteiro de entrevista semiestruturado. Todas as entrevistas foram audiogravadas mediante consentimento para posterior análise.

\section{Análise dos dados.}

As entrevistas foram transcritas na íntegra e literalmente, compondo o corpus de análise. Foi realizada uma análise de conteúdo temático, com a construção de categorias a posteriori e tomando por base a leitura flutuante (primeiro momento) e minuciosa (segundo momento) do corpus, a partir dos principais sentidos trazidos sobre a prática da benzeção na interface com as histórias de vida das participantes. O próximo passo consistiu na análise vertical (caso a caso) e horizontal (integrando os casos) das entrevistas, utilizando como parâmetro estudos sobre o desenvolvimento humano a partir da perspectiva da Rede deSignificações-RedSig (Rossetti-Ferreira, Amorim, \& Silva, 2004) e com respaldo na literatura científica existente sobre o tema (Oliveira, 1985; Quintana, 1999; Silva, 2007; Nogueira, Versonito, \& Tristão, 2012; Theotonio, 2010), em diálogo com a etnopsicologia (Bairrão, 2004; Boyer, 1996; Helman, 2009; Laplantine, 2010; Macedo, 2015; Scorsolini-Comin, 2015). A RedSig é um arcabouço teórico-metodológico para as pesquisas em Psicologia do Desenvolvimento que recupera as contribuições de autores como Bronfenbrenner, Vigotski, Wallon e Bakhtin, em uma perspectiva que considera o desenvolvimento como dando-se ao longo de todo o ciclo vital, a partir de múltiplas interações como os outros sociais e as práticas discursivas presentes em nossa cultura. Nesse processo, diversas significações são (re)(des)construídas dialogicamente, referendando a complexidade das interações que nos constituem. As categorias construídas a partir da análise de conteúdo, explicitadas na seção de Resultados e Discussão, foram: (1) Histórias de vida e desenvolvimento como benzedeiras; (2) A transmissão do ofício; e (3) As benzedeiras e suas redes de significações.

\section{Resultados e Discussão}

Durante a coleta de dados, observou-se predomínio das benzedeiras nos bairros periféricos dos municípios, justamente onde se concentra a maior parte de pessoas com menor poder aquisitivo, e tam- 
bém aquelas que se mudaram de sítios para a cidade após muito tempo de convivência no ambiente rural. Há que se destacar que os municípios nos quais foram realizadas as entrevistas possuem ligação com o meio rural, sendo conhecidas como cidades interioranas, ainda que com forte marca do processo de urbanização. As benzedeiras entrevistadas são referências em toda a região de suas comunidades, e atendem a pessoas de cidades vizinhas, e até mesmo regiões distantes. Ressalta-se aqui que o termo "benzedeiras" será utilizado no gênero feminino neste estudo devido à característica da amostra entrevistada, sendo mulheres em sua totalidade. Embora a seleção apenas de benzedeiras do sexo feminino não tenha sido intencional, destaca-se que este foi o perfil construído a partir do recrutamento realizado. Isso confirma o predomínio das mulheres que realizam essa prática, em um processo de feminilização do ofício da benzeção (Medeiros et al., 2013). Sobre a religião das entrevistadas, temos que oito delas professavam a religião católica, sendo uma umbandista e uma evangélica. Algumas características se repetem entre a maioria das participantes, como a baixa renda e a pouca escolaridade. Quanto à profissão, todas as entrevistadas se dizem donas de casa, embora a maioria já tenha exercido trabalho como agricultoras, domésticas e babás. A caracterização das respondentes é sumarizada na Tabela 1 .

\section{Histórias de vida e desenvolvimento como benzedeiras}

Foram percebidos nas narrativas das participantes alguns elementos em comum. Logo quando foram solicitadas a falarem sobre suas histórias de vida, da maneira como julgassem melhor, notou-se uma tendência das participantes em iniciar seus relatos falando sobre o período da infância. Tal fase, para a maioria das entrevistadas, foi um período de muito sofrimento, mas que foi recordado nostalgicamente. Segundo os relatos, a maioria começou a trabalhar desde muito nova, contando com orgulho suas batalhas superadas e também as dificuldades passadas por suas famílias. Destaca-se a grande repercussão do ambiente rural na vida dessas mulheres, que ou cresceram em contato direto com esse ambiente, ou foram influenciadas por pessoas de origem rural.

Existem diversas concepções, tanto na literatura, quanto no discurso das entrevistadas, a respeito do conceito de "dom". No contexto das religiões de matriz africana, no Brasil, Boyer (1996) destaca o dom como algo que pode ser considerado inato e que, muitas vezes, dispensaria a necessidade de um processo de iniciação. A descoberta desse dom é vista pelas benzedeiras como uma missão de Deus a ser cumprida (Nogueira, Versonito, \& Tristão, 2012; Oliveira, 1985; Silva, 2007). O modo como esse dom é transmitido, no entanto, oscila entre algo recebido de Deus (e, portanto, inato) e algo transmitido a partir dos ensina-

Tabela 1

Caracterização das participantes $(N=10)$.

\begin{tabular}{lccccc}
\hline Nome fictício & Idade (anos) & Tempo de atuação (anos) & Escolaridade & Estado civil & Religião \\
\hline Érica & 61 & 38 & Fundamental incompleto & Viúva & Católica \\
Dona Maria & 76 & 64 & Analfabeta & Viúva & Católica \\
Cleide & 49 & 32 & Fundamental incompleto & Solteira & Umbanda \\
Ana & 52 & 15 & Médio completo & Casada & Católica \\
Dona Beatriz & 48 & 11 & Médio incompleto & Solteira & Evangélica \\
Deise & 67 & 6 & Fundamental incompleto & Solteira & Católica \\
Helena & 65 & 15 & Fundamental incompleto & Casada & Católica \\
Dona Gertrudes & 61 & 8 & Fundamental incompleto & Casada & Católica \\
Dona Silvia & 77 & 33 & Fundamental incompleto & Viúva & Católica \\
Edna & 69 & 40 & Fundamental completo & Viúva & Católica \\
\hline
\end{tabular}


mentos de outra benzedeira (Oliveira, 1985; Quintana, 1999). Para Moura (2009), a transmissão feita por laços de parentesco é a mais comum. Nesses casos, o dom é passado para um familiar que apresente as características necessárias para a prática, tais como: interesse, respeito e convivência com aquele que já benze (mãe, tia, madrinha ou uma rezadeira da própria redondeza) (Theotonio, 2010). Para Helman (2009), o reconhecimento do "dom" da benzedeira e sua transmissão pode se dar de diferentes modos, como a partir dos ensinamentos na própria família, por parte de um curandeiro mais experiente não necessariamente com laços de parentesco, por meio de sonhos, presságios, intuições, entre outras possibilidades. Das 10 benzedeiras entrevistadas, oito descreveram a transmissão por meio da família. Esse aprendizado é lembrado pelas rezadeiras como parte de sua infância e adolescência, sendo que alguns trechos de suas narrativas serão trazidos para ilustrar essa dinâmica:

A minha história de vida, eu acho que foi uma história bonita, porque foi uma história de família, né? Isso de benzer vem desde o tempo dos meus avós, meus avós passaram pros meus pais e os meus pais passou pra gente. Minha mãe benzia muito, né? Ela chamava eu lá e quando ela benzia, ela me ensinava, porque ela já tava meio de idade e então eu aprendi com ela. Eu sempre falava pra ela que quando ela não quisesse mais, era pra ela me ensinar que eu queria aprender (Deise).

A dinâmica da transmissão familiar acaba se solidificando posteriormente, mas inicialmente, vê-se que, ainda quando crianças, essas mulheres já exibiam comportamentos relacionados ao ato de benzer, ao brincar ou atuar os rituais aos quais eram expostas durante a infância e adolescência. Segundo Quintana (1999), é por meio dessa "brincadeira" que o processo vai se tornando eficaz e vai sendo reconhecido no meio familiar como um dom.

Então desde pequena, eu gostava de ficar vendo a minha mãe benzer as pessoas. Eu nem entendi o que ela fazia direito, mas gostava muito de ver. Às vezes, eu brincava sozinha de pegar terço, ramo, água... e brincava sozinha fingindo que tava benzendo. Aí quando a minha mãe começou a ficar doente, ela perguntou se eu tinha interesse em ajudar ela, e nem precisou falar duas vezes (Edna).
Além desse tipo de transmissão por parentesco, Moura (2009) e Helman (2009) ressaltam que o dom também pode ser adquirido por meio de uma revelação, seja em sonho ou por uma visão espiritual. Esse é o caso de duas entrevistadas:

Bom, quando eu era criança, eu tinha uns cinco, seis anos, eu já via coisa, eu sentia a presença de coisa, e fui vivendo com aquilo. E, às vezes, eu brincava, sempre que eu brincava com as crianças eu gostava de brincar de benzer. Depois eu comecei a trabalhar no centro, e foi acontecendo naturalmente as coisas, é uma coisa que vem assim, de repente assim (Cleide).

$\mathrm{Na}$ aprendizagem pela experiência mística, os conhecimentos tanto das orações como de plantas são atribuídos à informação de alguma entidade sobrenatural, como anjos ou guias, principalmente (Quintana, 1999). No caso das entrevistadas desse estudo que relataram ter passado pela transmissão por alguma experiência mística, a benzedeira umbandista apontou os "pretos-velhos" como guias, enquanto a benzedeira evangélica se reporta a "Deus, que se revela na palavra".

Que nem... se eu vou ler uma palavra pra uma pessoa e Deus fala: "Lê São João, 14, salmo 23 ou salmo 70", eu tenho que abrir a página e lê, porque Deus fala, ele revela na palavra (Beatriz).

Eu não faço nada, eu costumo dizer que eu sou só um corpo emprestado. Quem faz tudo é eles, os preto-véio e Deus, com a permissão de Deus, porque se Deus não permitir, eles não vem e aí não cura (Cleide).

Mais uma vez encontramos correspondências entre a literatura nacional e internacional sobre o desenvolvimento das pessoas que fazem uso dessas práticas de cura populares. Segundo Krippner e Villoldo (1986), alguns xamãs são iniciados quando herdam o papel enquanto outros podem exibir sinais corporais, ações incomuns, experiências estranhas, como sensações de estar "fora do corpo" e sonhos vívidos e lúcidos ou, ainda, segundo Heinze (1991), podem sobreviver a uma doença quase fatal e interpretar esse fenômeno como um "chamado", um presságio. 
Quintana (1999) destaca uma situação bem comum na narrativa das participantes: o enfrentamento de acometimentos da saúde física através do desenvolvimento do dom de benzer. Passar por essas dificuldades e problemas de saúde e conseguir recuperar seu equilíbrio físico e espiritual através dessas experiências místicas, significaria que, de fato, aquela pessoa foi designada para uma missão: primeiramente no sentido de ter sido escolhida e, segundo, por passar a ter qualidades que anteriormente não tinha. O sentido de saúde enquanto equilíbrio entre diferentes partes que compõem o humano aparece fortemente nas comunidades nas quais as benzedeiras executam suas práticas populares de cuidado (Helman, 2009). Nas entrevistas realizadas, foi identificado um caso como o descrito por Quintana (1999) na narrativa de vida de Beatriz:

Quando eu fui orar pro povo na minha casa, eu fiquei paraplégica. $\mathrm{O}$ inimigo me deixou paraplégica porque ele não queria que orasse pra ninguém. Aí Deus me deu um sonho, um médico chegou e disse assim: "olha, você nunca mais vai andar, seus ossos estão tudo que nem um cristal", e Deus me deu um sonho assim de eu sentada na minha cama e uma pessoa chorando, e eu colocava a mão na cabeça dela e aquela pessoa começava... não queria mais se matar, começava a me abraçar. Aí eu acordei e chamei meu filho e falei assim: "me dá um banho e me leva lá pra fora, a partir de hoje, pega o meu celular e uma agenda que eu vou começar a marcar pessoas", e aí eu comecei a orar pras pessoas sentada.

O enfrentamento de situações de adoecimento também aparece em relatos de médiuns da umbanda, tanto em seu processo de preparação mediúnica quanto na decisão por se dedicar à atividade espiritual, o que frequentemente é compreendido como uma "missão" que deve ser cumprida e que se insere no ciclo vital (Macedo, 2015; Scorsolini-Comin, 2015). Os aprendizados inerentes a esse ofício são transmitidos pela mediunidade em contatos com o plano espiritual por meio de sonhos, transes de possessão e consultas com outros médiuns e guias. Assim, trata-se de uma aprendizagem a partir de elementos que não são controlados pelo aprendiz, mas que se cravam em sua experiência e se refletem em seu ofício.

Algumas benzedeiras relataram não terem sentido interesse pela prática logo de imediato, como
Maria e Gertrudes. O que fez com que elas iniciassem seus atendimentos foi a pressão social ou por terem sentido o chamado para essa missão. Além disso, ao serem constatadas as primeiras curas e ao serem reconhecidas dentro de suas comunidades, as benzedeiras passaram a valorizar cada vez mais essa atividade, o que destaca o meio como importante elemento na construção da identidade das benzedeiras. A legitimidade dessas práticas, associada a alguma observação de eficácia, constitui algo de suma importância na difusão e no reconhecimento social das práticas populares em saúde (Helman, 2009).

Foi assim: a mãe do meu esposo era benzedeira, a minha sogra. Então ela falava: "quando eu morrer, eu vou deixar o benzimento pra você continuar”, eu falava: "não Dona Maria, não vou continuar esse benzimento". Aí ela falava que eu que ia benzer, e eu falava que não, que era pra ela passar pros filhos dela, mas ela falava que tinha que ser pra mim. Aí ela faleceu, e falou pra mim que era pra eu benzer... e depois eu não benzia não. Aí, depois de ela ter morrido, eu sonhava muito com ela, ela aparecia no sonho e falava assim pra mim: "aquelas criança lá vem vindo aqui pra você benzer", aí eu olhava aqui de fora e tinha aquele monte de criança, e eu falava que ia esconder pra não benzer. Aí eu falei que o jeito era benzer né... fazer o quê? aí foi eu decidir que ia começar que depois disso eu não sonhei mais com ela (Gertrudes).

O dom acompanha as benzedeiras desde o momento em que se sentiram responsáveis por realizarem as práticas que foram ensinadas a elas ou que por elas foram desenvolvidas. Segundo Pereira (1993), o dom representa certo privilégio ao dotar o escolhido de um poder especial, mas também representa um compromisso, uma missão que ordena a vida das benzedeiras e da qual a escolhida não pode fugir. Essa ideia é reforçada por diversos autores (Helman, 2009; Quintana, 1999; Silva, 2007) que defendem que a atividade de benzer outras pessoas requer muito sacrifício e disciplina, sendo esse um dos principais motivos de resistência em iniciar as práticas de cura. Esse compromisso ético com a missão recebida atravessa os estudos sobre mediunidade, sendo um fenômeno de uma dimensão não material que repercute na concretude das relações sociais e interpessoais das pessoas "escolhidas" (Macedo, 2015). Tal missão emerge como um 
elemento desenvolvimental potente, circunscrevendo os percursos dessas pessoas, promovendo transições ecológicas (Rossetti-Ferreira et al., 2004), como o surgimento de uma nova função social - a de benzedeira, nesse caso. As transições ecológicas, tal como apresentadas originalmente por Bronfenbrenner (2002), referem-se a mudanças de papel ou de ambiente, e é a partir dessas mudanças que se pode apreender os processos desenvolvimentais. Essas transições ocorrem ao longo de todo o ciclo vital dos sujeitos e caracterizam tanto uma consequência do desenvolvimento quanto uma motivação para este. Nesse novo papel, emergem novos desafios e responsabilidades.

Requer muita paciência, você tem que deixar muita coisa de lado pra poder atender. $\mathrm{E}$ a benzição não tem dia, não tem hora (Gertrudes).

Mas eu acho que o mais difícil foi deixar a sua vida pra ajudar os outros... é muito bonito, mas às vezes isso pesa um pouco. Que nem... já chegou gente aqui em casa de madrugada, de sábado, de domingo, de feriado, com chuva ou sol, que eu tive que largar as minhas coisas, meus filhos, meus planos pra atender (Edna).

O sacrifício pode ser compreendido como uma forma de ter influência sobre o sagrado, como se a pessoa assumisse uma “dívida” com ele (Callois, 1998). Quando questionadas a respeito da possibilidade de cobrar um pagamento pelo serviço prestado, todas as entrevistadas condenaram em suas respostas esse tipo de prática e demonstraram desconforto ao falar sobre essa situação. Segundo elas, o dom de benzer é algo concebido por Deus e que não pode ser cobrado visando o benefício próprio. Isso vai ao encontro com o que a literatura defende ao dizer que o sagrado não pode ser vendido, já que quem atua como benzedeira recebe o dom gratuitamente de Deus (Silva, 2007). Essa questão da prática da caridade, na visão de Quintana (1999), relaciona-se com a maneira como é visto o processo de obtenção de cura, que é alcançada através da intervenção divina.

\section{A transmissão do ofício}

A transmissão de conhecimentos é um momento delicado na trajetória de uma benzedeira, pois é dessa forma que são perpetuadas suas práticas e valores para as próximas gerações, reafirmando a importância desse trabalho em suas comunidades. Metade das entrevistadas demonstrou interesse em repassar seus conhecimentos, embora ninguém ainda as tenha procurado com essa intenção. Apenas uma entrevistada alegou não ter interesse em repassar seus conhecimentos. Além disso, duas entrevistadas já ensinaram outras pessoas e continuaram benzendo, e outras duas participantes afirmaram não ser possível ensinar o ofício, já que este seria um dom nato a ser desenvolvido.

Existem basicamente duas concepções acerca da transmissão de conhecimentos para as benzedeiras católicas: aquela que defende que a transmissão do conhecimento tem como consequência a interrupção das atividades da atual benzedeira, e outra que acredita que, mesmo após a transmissão, a benzedeira atual poderia continuar a curar pessoas. Pode-se observar, a partir do relato das entrevistadas e dos resultados de estudos anteriores sobre o tema, que existe uma infinidade de possibilidades a serem consideradas sobre o momento da transmissão dos conhecimentos e também dos diversos rituais de iniciação (Boyer, 1996). Vemos que, entre as entrevistadas, apenas uma defende que a interrupção é necessária após a transmissão de conhecimentos. Por outro lado, sete entrevistadas acreditam que nada as impediria de continuar seus benzimentos; entretanto, existem ressalvas a serem feitas em alguns casos: Helena declarou que alguns tipos de benzimentos permitem a continuidade após a transmissão e outros que não permitem, mas a entrevistada não soube responder qual o motivo dessa diferenciação. Já Silvia relatou que acredita que pode ensinar suas orações, com exceção de uma delas, que deve ser mantida em segredo para resguardar a força de cura da benzedeira. Ademais, como já foi dito, as duas participantes não católicas não consideram o benzimento algo que possa ser ensinado e aprendido. Assim, a maioria das benzedeiras não encontram problemas em seguirem com suas práticas, corroborando os dados de Theotônio (2010), que afirma que o dom não é extinto ou diminuído após o ensinamento dos conhecimentos. Nesses casos, o que impediria a benzedeira de continuar exercendo seu papel seriam a idade e as complicações de saúde.

Quando questionadas a respeito do motivo pelo qual a transmissão de conhecimentos teria tais consequências, a maioria das entrevistadas não soube responder, dizendo que executam e repassam o que 
aprenderam. Essa é uma característica de benzedeiras em geral, que muitas vezes não são capazes de explicar o motivo ou justificativa para suas práticas, alegando que "sei porque me ensinaram assim" ou "foi assim que eu aprendi", o que revela, muitas vezes, que os aprendizados e as transmissões sustentam-se na oralidade. A respeito disso, Silva (2007) diz que esses saberes são adquiridos pela observação, repetição, na vivência cotidiana com quem possui esta sabedoria e, principalmente, por meio da experiência e da tradição oral. E justamente por representarem um conhecimento empírico, não carecem de justificativas científicas para sua permanência, sendo que a comprovação é baseada nas experiências e na legitimação no seio social. Assim, a eficácia da prática mostra-se mais relevante para o cliente do que a explicação do fenômeno (Helman, 2009). Essa repetição rotineira de determinados rituais de cura, por exemplo, alicerça-se na importância de um método que, segundo elas, possui uma eficácia (Medeiros et al., 2013). Eficácia esta, obviamente, que nem sempre pode ser atestada pelo crivo científico, mas pela crença da benzedeira, do consulente e no reconhecimento público de seu poder, "que formam continuamente uma espécie de campo de gravitação no interior do qual se situam as relações entre o feiticeiro e aqueles que ele enfeitiça" (Lévi-Strauss, 1975, p. 182).

É importante ressaltar o alto nível de preocupação das benzedeiras que decidem repassar seus conhecimentos no momento da escolha de seu sucessor. A preocupação se resume em encontrar alguém que seja de confiança e que esteja realmente interessado em aprender e levar sua prática adiante com fidedignidade e dignidade, uma vez que juntamente com seus conhecimentos serão repassados seu nome, sua reputação, o trabalho de sua vida e, por extensão, sua própria identidade. Em estudo desenvolvido junto a uma mãe de santo, Leal de Barros (2015) destaca que a transmissão do ofício espiritual ocupa um lugar importante no modo como uma comunidade irá perpetuar suas referências em torno do sagrado, do cuidado e da rede de apoio social construída pelo líder espiritual. Essa transmissão, no contexto religioso analisado, dar-se-ia inclusive em nível psíquico, como forma de uma herança transgeracional passada de mãe para filha. No caso das benzedeiras não foi observado esse encargo da transmissão, mas igualmente um processo de tensão no que se refere à continuidade ou não do ofício e dos serviços prestados.
Por fim, um dos pontos percebidos como agravantes pelas entrevistadas sobre o momento da transmissão de conhecimentos é a falta de interesse dos mais novos para com esse tipo de prática. Quando foram perguntadas a respeito da existência de mudanças na fé das pessoas mais novas com relação às mais velhas, nove delas afirmaram terem percebido uma "diminuição na fé dos jovens" e uma mudança qualitativa da fé, como se ela atualmente estivesse relacionada ao interesse econômico e aos benefícios da benzeção. Ilustra-se essa preocupação no seguinte trecho: "Ah, mudou muito, né? Eu acho que hoje em dia tem bastante gente que tem fé boa mesmo, mas parece que hoje em dia tem uma fé que é meio comprada. Parece que é uma fé interessada em algo" (Helena).

O receio ressaltado pelas participantes é o desinteresse dos jovens por essas práticas, o que faz com que esses conhecimentos fiquem restritos às populações mais idosas. Por já se encontrarem em estágios avançados do desenvolvimento humano, as benzedeiras sentem necessidade de repassar o quanto antes seus saberes para outras pessoas. Essa seria uma forma de perpetuar e de garantir todo o bem que elas fizeram durante sua vida, também como uma forma de permanência de seu modo de ser, suas contribuições e seu poder.

É uma pena que a benzição tá acabando, porque os novo não tão querendo aprender, e os velhos... uns tá doente, outros morreu... então tá acabando (Gertrudes).

É uma coisa que precisa mais... esse interesse dos mais novos, porque se não a coisa morre com a gente, né? Se Deus me permitir eu pretendo ensinar pra mais gente que quiser aprender, e se der tempo eu quero aprender a benzer mais coisa também (Edna).

Na contemporaneidade, embora se reconheçam as subculturas de cuidado sob a forma de um sistema popular (folk) de saúde, como no caso das benzedeiras, há que se observar o papel cada vez maior da industrialização, da urbanização e, consequentemente, de acesso a conhecimentos formais e profissionais em saúde que, de certo modo, podem obscurecer ou mesmo relegar a um segundo plano os conhecimentos populares construídos e transmitidos em todas as culturas e sociedades. Esse processo acaba por con- 
tribuir para que tal ofício venha perdendo espaço em muitas comunidades. A "profissionalização" do ofício, como mencionado por Helman (2009), que envolve o reconhecimento dessa atuação por parte dos profissionais de saúde, por exemplo, muitas vezes acaba submetendo esses conhecimentos a um novo crivo de análise e a uma lógica do sistema formal, a uma representação exclusivamente biomédica de doença (Laplantine, 2010). Assim, as etnoteorias que explicam a doença, a saúde e a cura, transmitidas em uma dada cultura, passam a ser analisadas por uma lógica que justamente desconsidera a multiplicidade de representações sociais, culturais e psicológicas que explicam a assunção das benzedeiras e o modo como atravessam e delimitam o conceito de cuidado em diversas comunidades. Em outras palavras, a dificuldade de transmitir o ofício aos mais jovens pode revelar a submissão da benzeção a uma lógica biomédica, dentro de um sistema formal de saúde que, por vezes, negligencia os sistemas populares de cuidado.

\section{As benzedeiras e suas redes de significações}

Tomando por base a Rede de Significações, considera-se que as práticas das benzedeiras são constantemente interpretadas pelos próprios pares das comunidades em que esses indivíduos estão inseridos. Segundo Rossetti-Ferreira et al. (2004), é por meio de constantes processos dialógicos que cada pessoa tem seus comportamentos delimitados, recortados e interpretados pelos outros e por si próprio, através da coordenação de papéis ou posições dentro de contextos específicos. Sendo assim, é a partir desses processos dialógicos de interação e interpretação que as benzedeiras vão, por muitas vezes, sendo "enquadradas" em perfis e acabam assumindo de fato as características que são difundidas por seus pares. A eficácia atribuída pelo coletivo (Lévi-Strauss, 1975) confere a certeza de que o ofício não apenas é bem desempenhado, mas que também aquele determinado papel assumido pela benzedeira constitui um locus de poder, de credibilidade e de possibilidade de referência para a comunidade ao seu entorno em termos de cura e de promoção de saúde e bem-estar.

Como resultado desse processo contínuo no presente, que revive constantemente o passado e influencia o futuro, as entrevistadas são vistas como mulheres dedicadas, disciplinadas e que estão sempre dispostas a ajudar, sendo possuidoras de alto nível de conheci- mento, além de um caráter místico, o que causa certa antipatia por parte daqueles que não conhecem seus trabalhos. Muitas vezes a benzedeira é conselheira, parteira, raizeira e desempenha um papel consultivo e de destaque no que se refere, por exemplo, a práticas de cura e de promoção de saúde; e na união desses papéis conquistam o respeito em suas comunidades, operando uma lógica que amplia a representação dos sistemas exclusivamente formais, profissionais e biomédicos de saúde e cuidado. Em consonância com a maioria da amostra deste estudo, Oliveira (1985) traz que a imagem de uma benzedeira geralmente é a de uma mulher casada, mãe de alguns filhos, pobre, que conheça rezas, ervas e massagens, cataplasmas, chás e simpatias, e que tenha "um quê de mistério", que lide com a "magia". Para além desses aspectos, representa uma importante fonte de apoio no que tange às práticas de saúde popularmente veiculadas nas suas comunidades de referência, uma vez que prescrevem o emprego de uma medicina popular e alternativa, baseada na transmissão oral, o que não pode ser analisada em termos de sua eficácia científica - e reforçaria a exclusividade da lógica biomédica, segundo Laplantine (2010), mas sim das representações veiculadas acerca do que é saúde, cura, bem-estar e fontes de apoio.

Muitos vê a gente como macumbeira, filha do diabo, outros vê a gente como uma pessoa que quer ajudar. É dividido [risos] (Cleide).

Ah, os que conhecem o que eu faço acha bom, elogia, porque sabe que é coisa do bem. Agora, que nem eu te falei, tem uns que confundem achando que eu faço outras coisas ruim, vem aqui pedindo, pede se eu sei alguém que faça... mas isso eu não faço, é atraso de vida (Gertrudes).

E eu me sinto feliz, eu saio na rua assim, eu nem sei quem é mas me chamam de vó, com carinho, me mostram que as criança tão boa... então eu me sinto muito feliz (Maria).

Nota-se, assim, que as pessoas ainda possuem uma concepção ambivalente das benzedeiras, acreditando que são pessoas dispostas a ajudar, mas que também podem prejudicar quando intencionadas a fazerem isso. Essa desconfiança, por vezes, é gerada por meio dos sistemas formais de cuidado e dos profissionais de saúde que desconsideram esses saberes 
(Helman, 2009) ou mesmo a partir de uma tradição cultural que as coloca como pessoas que também podem ser temidas, haja vista que lidam com o oculto e com o desconhecido (Boyer, 1996). Quando questionadas a respeito da visão que outras pessoas possuíam das suas práticas, as entrevistadas também variaram suas respostas, considerando desde o reconhecimento social e o carinho daqueles que conhecem seus trabalhos, mas também a confusão gerada por aqueles que os desconhecem e acreditam que elas seriam capazes de causar malefícios a alguém. No entanto, predomina a visão que as identificam como fontes de apoio e de promoção de saúde, representando práticas alternativas e complementares, não substitutivas dos aparelhos formais de saúde.

A partir dos processos dialógicos pelos quais as benzedeiras são submetidas durante todo o ciclo vital e das constantes interações e interpretações de si e dos outros que realizam, a visão da benzedeira sobre suas práticas vai se constituindo. Segundo Rossetti-Ferreira et al. (2004), é esperado que o indivíduo seja constituído por múltiplas vozes e influências que vão sendo exercidas ao longo da vida. É essa multiplicidade de vozes e posições que dialogam entre si e possibilitam a abertura para a construção de novos posicionamentos e processos de significação acerca do mundo, do outro e de si.

Os resultados encontrados nas entrevistas das participantes sobre a visão de si são consonantes com a literatura (Quintana, 1999; Theotonio, 2010). Segundo esses autores, as pessoas que aceitaram a missão de atuar como benzedeiras devem estar dispostas a ajudar e devem desvincular sua prática do benefício próprio, visando ao atendimento daqueles que as procuram e de sua comunidade local. A partir da descoberta do dom que a benzedeira passa a se diferenciar dos demais, construindo sua identidade social. Assim, opera-se um reconhecimento coletivo e uma validação da comunidade acerca das práticas exercidas pelas benzedeiras, publicamente associadas à promoção de saúde, cuidado e bem-estar.

Considerando a diferenciação de visões trazidas pelos dados de Silva (2007) com relação à interrupção da prática após o processo de transmissão de conhecimentos, percebeu-se que aquelas benzedeiras que defendem a interrupção da prática após a transmissão tendem a se reconhecer como pessoas que possuem o dom da cura através das suas orações. Já as benzedeiras que não acreditam na interrupção de suas prá- ticas são aquelas que se percebem como um instrumento, sendo apenas um mecanismo que o divino e a fé encontraram para curar as pessoas (Borges et al., 2009). Entretanto, houve uma discrepância nesse caso para as entrevistadas desse estudo. Nota-se que todas as entrevistadas se percebem apenas como um instrumento do poder divino, retirando de si a conotação de serem poderosas ou mágicas.

Eu não me sinto importante não, me sinto a humilde que eu sou mesmo... mas eu sinto muito bem de poder ajudar as pessoas né, só de ajudar (Érica).

Uma pessoa normal, né, filha. A única coisa é que eu tô ali pra ajudar sempre, eu com a minha fé consigo pedir por sua ajuda. Eu gosto, me sinto bem em poder ajudar tanta gente, sei que já ajudei muita gente... e que eu também já sou conhecida por fazer isso. Mas eu não me sinto poderosa, nem especial não... porque isso quem é, é Deus. Eu me sinto querida, e bem (Edna).

É muito comum, tanto na literatura quanto no encontrado nas entrevistas, que essas pessoas sintam certa repulsa a serem nomeadas como curandeiras ou benzedeiras. Segundo Oliveira (1985), ao pressentirem esses rótulos, as pessoas buscam meios de resgatar o outro lado de suas identidades usando adjetivos bondosos e termos que expressem de fato o trabalho que eles realizam.

Eu também não me dou título de benzedeira, eu acho uma coisa muito... como eu posso te explicar... um rótulo, é um rótulo! E não, eu só ajudo as pessoas... esse negócio de benzedeira, nossa, parece que eu vou fazer um trabalho. Imagina o que vai na cabeça das pessoas, né? (Ana).

Muitas me vê como espiritista, macumbeira, vidente, adivinhadora, bruxa. Muitas pessoas já vieram aqui me falar, me chama de benzedeira, e eu não sou benzedeira. Eu sou evangélica, é um dom que Deus me deu (Beatriz).

É visto que a interpretação que o outro faz de suas práticas ainda é levada em consideração por essas benzedeiras, que precisam deixar claro as atividades que realizam e seus objetivos para poderem se reafirmar como boas e caridosas dentro 
de suas comunidade. Tais confusões semânticas também podem encontrar ressonância no fato de que a representação social da figura da benzedeira nem sempre é associada com as atividades que elas desempenham. Em um panteão religioso habitado pela diversidade de credos, entidades e experiências religiosas, tal como se apresenta no contexto brasileiro (Bairrão, 2004), é possível encontrar diferentes significações e explicações para essas práticas, como a própria relação com uma religião específica, no caso de Beatriz. Ainda que tais práticas não sejam recorrententes ou talvez nem sejam legitimadas pela comunidade evangélica, Beatriz parece destacar sua religião como forma de conferir certo distanciamento ou idoneidade ao seu ofício. Isso nos obriga a relativizar tais achados, na consideração de uma diversidade de formas de corporificar o ofício da benzeção. Em um contexto religioso multifacetado e mestiço, essas práticas mostram-se igualmente diversas e prenhes de oralidade, místicas e ressonâncias sociais da chamada "feitiçaria", no sentido trazido por Lévi-Strauss (1975).

Embora o desenvolvimento das benzedeiras seja um processo dialógico contínuo, no discurso das entrevistadas é comum surgirem momentos e episódios de vida considerados críticos, com os de descoberta do dom ou a aceitação da missão de servir a Deus. Tais momentos mostram-se marcantes por propiciarem maior desenvolvimento ou mesmo uma transição ecológica relacionada ao papel social desempenhado, ampliando as possibilidades de leitura das trajetórias dessas mulheres. O ofício da benzeção é corporificado na experiência de vida dessas mulheres, de modo que ser benzedeira é algo que está indissociado de outras características identitárias como ser mãe, mulher, avó, cidadã, dona de casa ou religiosa. Como marcador do desenvolvimento, tal ofício circunscreve algumas possibilidades, delineando um percurso de autoconhecimento e de constante estabelecimento de redes de apoio social.

Aí eu fui, comecei a desenvolver, comecei a trabalhar esse meu lado, melhorei muito, hoje eu sei quem eu sou, sei o porquê que eu vim fazer e sei o que eu quero. E quando eu vejo uma pessoa que está necessitada, não sei o que acontece, porque é uma coisa que a gente não tem explicação, a gente simplesmente benze as pessoas, benze as crianças e melhora (Cleide).

\section{Considerações finais}

Os processos de transformação observados nas e pelas participantes são responsáveis por permitir a expressão não apenas de uma identidade autocentrada (ser benzedeira), mas de reconhecimento e visibilidade por parte da comunidade. Assim, o ofício torna-se público, mostra sua importância e também o seu ônus no desenvolvimento e na vida cotidiana das benzedeiras.

Existe um apontamento, tanto na literatura quanto no discurso das benzedeiras, de que não seria qualquer pessoa capaz de se desenvolver e atuar como benzedeira. Pensando nisso, investigou-se juntamente com as participantes as características necessárias para que alguém pudesse se desenvolver e atuar como tal. As respostas variaram, mas destaca-se que, apesar de professarem religiões diferentes, todas apontaram a fé em Deus e o desenvolvimento da espiritualidade, o que inclui a disciplina e o sacrifício pessoal. Além desses elementos, foram apontados como requisitos para ser uma benzedeira: o dom para benzer, a vontade de ajudar os outros, a saúde física, o amor e a caridade. Essas mudanças decorrentes do ofício circunscreveram transições ecológicas (Bronfenbrenner, 2002) no desenvolvimento dessas mulheres e também repercutiram em suas comunidades de referência.

No contexto contemporâneo, a figura popular das benzedeiras tem sofrido modificações que tangem, por exemplo, as dificuldades de transmissão do ofício, a maior urbanização e, ainda, o maior acesso a sistemas formais de saúde e cuidado que nem sempre consideram, incorporam ou legitimam os sistemas considerados populares. E cada vez mais essas mulheres estão ocupando as periferias dos grandes centros ou mesmo cidades interioranas, havendo pouca consideração científica acerca do papel que podem desempenhar em suas comunidades de referência, quer seja como sinônimo de promoção de saúde e bem-estar, quer seja como rede de apoio e de acolhimento. Essas redes podem se estruturar em locais nos quais os equipamentos formais de ajuda nem sempre são acessíveis ou nem sempre atendem satisfatoriamente à demanda das populações mais necessitadas também em termos das representações de saúde, cuidado e doença compartilhadas nessas comunidades. Trazer à baila essas mulheres no presente estudo pode contribuir para que se desfaça, assim como anuncia o título do artigo, o "mau-olhado" por vezes atribuído a essas personagens, conferindo visibilidade às suas práticas e ao 
modo como se constroem como figuras respeitadas em suas comunidades e valorizadas por seus saberes populares, dentro de um sistema popular de cuidado muitas vezes negligenciado pelos sistemas formais e profissionais. Aponta-se, portanto, para a neces- sidade de maior visibilidade desse ofício em sua interface com o campo das práticas alternativas em saúde, ampliando as possibilidades de maior diálogo entre os sistemas de cuidado, em uma perspectiva de valorização, reconhecimento e pertencimento.

\section{Referências}

Bairrão, J. F. M. H. (2004). Espiritualidade brasileira e clínica psicológica. In V. A. Angerami-Camon (Org.), Espiritualidade e prática clínica (pp. 193-214). São Paulo, SP: Thomson.

Borges, M. S. (2008). Incorporação do saber de parteiras e benzedeiras às práticas de saúde. Comunicação em Ciências da Saúde, 19(4), 323-332.

Borges, M. S., Shimizu, H. E., \& Pinho, D. M. (2009). Representações sociais de parteiras e benzedeiras sobre o cuidado. Ciência, Cuidado e Saúde, 8(2), 257-263. https://doi.org/10.4025/cienccuidsaude.v8i2.8207

Boyer, V. (1996). Le don et l'initiation: de l'impact de la littérature sur les cultes de possession au Brésil. L'Homme, 36(138), 7-24. Recuperado de http://www.persee.fr/doc/hom_0439-4216_1996_num_36_138_370072

Bronfenbrenner, U. (2002). A ecologia do desenvolvimento humano: experimentos naturais e planejados (M. A. V. Veronese, trad.). Porto Alegre, RS: Artmed.

Callois, R. (1988). O homem e o sagrado. Lisboa: Edições 70.

Campos, E. (1967). Medicina popular do Nordeste: superstições, crendices e meizinhas (3a ed.). Rio de Janeiro, RJ: O Cruzeiro.

Heinze, R.I. (1991). Shamans of the 20th century. New York, NY: Irvington.

Helman, C. G. (2009). Cultura, saúde e doença (5a ed., A. R. Bolner, trad.). Porto Alegre, RS: Artmed.

Krippner, S., \& Villoldo, A. (1986). The realms of healing (3rd ed.). Berkeley, CA: Celestial Arts.

Laplantine, F. (2010). Antropologia da doença (4a ed., V. L. Siqueira, trad.). São Paulo, SP: Martins Fontes.

Leal de Barros, M. (2015). Mulher e mãe (de santo): transmissão psíquica geracional e elaboração de feminilidade na "passagem do bastão". Cultures-Kairós, 5, 1-18. Recuperado de http://revues.mshparisnord.org/cultureskairos/index.php?id=1059

Lévi-Strauss, C. (1975). Antropologia estrutural. Rio de Janeiro, RJ: Tempo Brasileiro.

Lins, D. (2013). A benzeção em Santa Maria: a permanência de tradições de cura no contexto da contemporaneidade. Revista Latino-Americana de História, 2(6), 569-581. Recuperado de http://projeto.unisinos.br/rla/index. $\mathrm{php} / \mathrm{rla} /$ article/view/216/170

Macedo, A. C. (2015). Encruzilhadas da interpretação na umbanda (Tese de doutorado). Faculdade de Filosofia, Ciências e Letras de Ribeirão Preto. Universidade de São Paulo, Ribeirão Preto, SP.

Medeiros, R. E. G., Nascimento, E. G. C., Diniz, G. M. D., \&Alchieri, J. C. (2013). Na simplicidade a complexidade de um cuidar: a atuação da benzedeira na atenção à saúde da criança. Physis: Revista de Saúde Coletiva, 23(4), 1339-1357. https://doi.org/10.1590/S0103-73312013000400016

Moura, E. C. D. (2009). Entre Ramos e Rezas: o ritual de Benzeção em São Luiz do Paraitinga, de 1950 a 2008 (Dissertação de mestrado). Pontifícia Universidade Católica, São Paulo, SP.

Nogueira, L. C., Versonito, S. M., \& Tristão, B. D. (2012). O dom de benzer: a sobrevivência dos rituais de benzeção nas sociedades urbanas: o caso do município de Mara Rosa, Goiás, Brasil. Elisée, 1(12), 167-181. Recuperado de http://www.revista.ueg.br/index.php/elisee/article/view/1290

Nunes, M. F., Magalhães, M. L., \& Rocha, A. L. C. (2013). Trabalho negro, memória negra no Vale do Sinos (RS): narrativa etnobiográfica de Vó Nair. Horizontes Antropológicos, 19(39), 269-292. https://doi.org/10.1590/S0104-71832013000100011

Oliveira, E. R. (1985). O que é benzeção. São Paulo: Brasiliense. 
Pereira, M. L. G. (1993). Fazendo parto, fazendo vida: doença, reprodução e percepção de gênero na Amazônia (Dissertação de mestrado). Pontifícia Universidade Católica, São Paulo, SP.

Quintana, A. M. (1999). A ciência de benzedura: mau-olhado, simpatias e uma pitada de psicanálise. Bauru, SP: Edusc.

Ribeiro, M. M. (1997). A ciência dos Trópicos. A arte médica no Brasil do século XVII. São Paulo, SP: Hucitec.

Rossetti-Ferreira, M. C., Amorim, K. S., \& Silva, A. P. S. (2004). Rede de significações: alguns conceitos básicos. In M. C. Rossetti-Ferreira et al. (Orgs.), Rede de significações e o estudo do desenvolvimento humano (pp. 23-34). Porto Alegre, RS: Artmed.

Rubert, G. C. M. (2014). A construção do sagrado: benzedeiras e práticas religiosas em Cambé/Paraná (Dissertação de mestrado). Universidade Estadual de Londrina. Londrina, PR.

Ryan, R.E. (1999). The strong eye of shamanism: a journey into the caves of consciousness. Rochester: Inner Traditions.

Scorsolini-Comin, F. (2015). "Ela não tem explicação, ela tem vida": a relação pesquisador-pesquisado no contexto de uma investigação etnopsicológica sobre mediunidade. Cultures-Kairós, 5, 1-17. Recuperado de http://revues. mshparisnord.org/cultureskairos/index.php?id=1071

Silva, G. S. (2007). Um cotidiano partilhado: entre práticas e representações de Raizeiros e Benzedeiros (Remanescente de Quilombo de Santana da Caatinga - MG / 1999 - 2007) (Dissertação de mestrado). Universidade de Brasília, Brasília, DF.

Simões, J. P. (2014). Benzedeiras de Maruípe: uma prática de cuidado humano em extinção (Dissertação de mestrado). Universidade Federal do Espírito Santo, Vitória, ES.

Theotonio, A. C. R. (2010). Entre ramos de poder: rezadeiras e práticas mágicas na zona rural de areia - PB (Dissertação de mestrado), Universidade Federal de Campina Grande. Campina Grande, PB.

Winkelman, M. (2002). Shamanism as neurotheology and evolutionary psychology. American Behavioral Scientist, 45(12), 1873-1885. Recuperado de http://journals.sagepub.com/doi/pdf/10.1177/0002764202045012010

\section{Raquel Cornélio Marin}

Psicóloga pela Universidade Federal do Triângulo Mineiro.

E-mail: raquelcmarin@hotmail.com

\section{Fabio Scorsolini-Comin}

Doutor em Psicologia pela Faculdade de Filosofia, Ciências e Letras de Ribeirão Preto da Universidade de São Paulo e Docente do Departamento de Psicologia e do Programa de Pós-Graduação em Psicologia da Universidade Federal do Triângulo Mineiro.

E-mail: fabioscorsolini@gmail.com

Endereço para envio de correspondência:

Programa de Pós-Graduação em Psicologia da Universidade Federal do Triângulo Mineiro. Rua Conde de Prados, 155, Abadia. CEP:38025-260.

Uberaba - MG, Brasil.

Este estudo recebeu o apoio do Conselho Nacional de Desenvolvimento Científico e Tecnológico (CNPq), por meio da concessão de bolsa de iniciação científica à primeira autora.

Recebido 01/07/2016

Reformulação 14/03/2017

Aprovado 05/04/2017

Received 07/01/2016

Reformulated 03/14/2017

Approved 04/05/2017 
Psicologia: Ciência e Profissão Abr/Jun. 2017 v. 37 n², 446-460.

Recebido 01/07/2016

Reformulado 14/03/2017

Aceptado 05/04/2017

Como citar: Marin, R. C., \& Scorsolini-Comin, F. (2017). Desfazendo o "Mau-olhado": magia, saúde e desenvolvimento no oficio das benzedeiras. Psicologia: Ciência e Profissão, 37(2), 446-460. https://doi.org/10.1590/1982-370302352016

How to cite: Marin, R. C., \& Scorsolini-Comin, F. (2017). Undoing the "Evil eye": magic, health and development in the craft of folk healers. Psicologia: Ciência e Profissão, 37(2), 446-460. https://doi.org/10.1590/1982-370302352016

Cómo citar: Marin, R. C., \& Scorsolini-Comin, F. (2017). Deshaciendo el “Mal de ojo”: la magia, la salud y el desarrollo eneloficiodelascuranderas. Psicologia:CiênciaeProfissão,37(2),446-460.https://doi.org/10.1590/1982-370302352016 